\title{
Os múltiplos fluxos na formação da agenda climática em Palmas e a participação de redes transnacionais de governos locais
}

\author{
Multiple streams on Palmas's climate agenda setting and the participation of \\ transnational networks of local governments
}

\section{Lia de Azevedo Almeida}

Doutoranda na Universidade de Brasília - PPGA/UnB, Professora da Universidade Federal do Tocantins - UFT e-mail: lia_aalmeida@hotmail.com

\section{Amilton Paulino Silva}

Doutorando e professor, Universidade de Brasília - UnB e-mail: amiltonps@globo.com

\section{Mônica Aparecida da Rocha Silva}

Doutora em Ciências Sociais, Professora da Universidade Federal do Tocantins - UFT e-mail:monicars@uft.edu.br

\begin{abstract}
RESUMO O objetivo é analisar como a problemática das mudanças climáticas foi introduzida na agenda municipal de Palmas, na gestão de (2001-2004), pois foi durante esta gestão que o município aderiu à campanha CCP do ICLEI e criou sua Política Municipal de Mudanças Climáticas. Para empreender tal análise foi utilizamos o modelo de Múltiplos fluxos de Kingdon. A partir da pesquisa bibliográfica empreendida, conclui-se que no início da gestão, o fluxo de problemas (queimadas, grandes vazios urbanos) articulouse com o fluxo político favorável às temáticas ambientais (criação de instituições e mecanismos para regular a temática ambiental) e alternativas eram geradas no fluxo de soluções (como o projeto de sequestro de carbono). A ligação dos três fluxos pode ocorrer a partir da presença de um empreendedor de políticas, o então, presidente do Instituto Ecológica, uma organização do terceiro setor com sede no município.
\end{abstract}

PalaVras-Chave Formação da agenda climática; Modelo de múltiplos fluxos; Palmas; ICLEI.

ABSTRACT The aim is to analyze how the issue of climate change was introduced in the agenda of Palmas, in the management (2001-2004), because it was during this administration that the city joined ICLEI's CCP campaign and created its Climate Change Policy. To undertake such analysis it was used the model of Multiple Streams. It was concluded that in the early management, the problems streams (fires, large urban voids) articulated with the politics streams that was favorable to environmental issues (creating institutions and mechanisms to regulate environmental issues) and alternatives were generated in the policy streams (such as carbon sequestration project). The connection of the three streams can occur from the presence of a policy entrepreneur, that was the president of the Ecological Institute, one third sector organization based in the city.

KEYWORDS Climate agenda- setting; Multiple streams model; Palmas; ICLEI. 


\section{Introdução}

No cenário contemporâneo, a questão das mudanças climáticas se tornou central no debate público e está presente na mídia diariamente (Giddens, 2009). A contribuição científica está, especialmente, representada nos relatórios formulados pelo Painel Intergovenamental de Mudança Climáticas (IPCC). A Convenção Quadro das Nações Unidas para as Mudanças Climáticas (CQNUMC) instituiu a base para as negociações multilaterais do clima. Entretanto, atualmente as negociações passam por dificuldades e os desafios centram-se no estabelecimento de um segundo período de compromissos para o Protocolo de Kyoto.

Paralelamente às negociações no regime internacional de mudança do clima, os governos subnacionais, de vários países, vêm há algum tempo tomando suas próprias ações no que concerne a questão climática, antecipando-se às normais nacionais ou internacionais (Lankao, 2007a). Neste sentido, os governos locais vêm procurando agir em conjunto, por meio da participação em redes transnacionais que reúnem municípios de diversas regiões do mundo e que buscam agir em temas relativos à sustentabilidade e às mudanças climáticas (Bulkeley e Betsill, 2003). Além de atuarem representando os interesses dos governos subnacionais nas negociações internacionais do clima, as redes, enquanto organizações, também trabalham a fim de criar capacidade local para que o município possa implantar medidas e políticas visando à proteção climática.

O Brasil, apesar de ter assumido uma postura ativa nas negociações internacionais do clima, só recentemente (2009) aprovou sua Política Nacional de Controle das Mudanças Climáticas, e não assumiu compromissos obrigatórios de redução de emissões de gases geradores do efeito estufa (GEE) na arena internacional. Por outro lado, há algum tempo já vem sendo registradas iniciativas de governos subnacionais brasileiros, no estabelecimento de políticas e medidas visando à proteção do clima. Porém, quando se fala em leis municipais, apenas uma pequena parcela de municípios pode ser mencionada. Conforme pesquisa realizada em 2009 pela CNM (Confederação Nacional dos Municípios), apenas 197 municípios (3,9\% do total) possuem projeto de lei, decreto ou lei para política municipal de mudanças climáticas, destes apenas 112 municípios (57\%) possuem uma lei ou decreto regulamentado, destes apenas 60 (54\%) apresentam uma meta específica de redução de gases de efeito estufa (CNM, 2009).

O município de Palmas foi o primeiro no Brasil a criar uma política municipal de mudanças climáticas, no ano de 2003, pouco depois de aderir à rede transnacional ICLEI. Além disso, outros programas que envolviam a temática das mudanças climáticas estavam em andamento na gestão municipal de (2001-2004). Atualmente, a população da cidade de Palmas é de 228.332 mil habitantes, com uma área de $2.219 \mathrm{~km}^{2}$, e densidade demográfica de 102,90 hab $/ \mathrm{km}^{2}$, sendo que $97,1 \%$ da população vivem em área urbana (IBGE, 2010). O município tem passado por um expressivo crescimento populacional. Outra característica do município são os grandes vazios urbanos, que desde sua constituição, contribui para a cidade possua o mais elevado custo per capita de urbanização do País, estimado no ano de 2005 em R\$ 216,79 (Bazolli, 2009). Em 2002, a cidade apresentava um elevado índice de área verde por habitante $280 \mathrm{~m}^{2}$ (PSCUP, 2002), em parte, pelas características de arborização previstas no seu plano diretor, e também pelos grandes vazios urbanos característicos do seu processo de ocupação. Isto leva ao questionamento do porquê da vanguarda do munícipio na temática das mudanças climáticas? Ou seja, porque o município que ainda não apresentava graves problemas/ameaças ambientais teve essa problemática inserida em sua agenda? Como esse tema chamou a atenção dos formuladores de políticas públicas e este passou a ocupar a agenda?

Nesse contexto, a proposta deste trabalho é compreender como se deu a inserção do tema das mudanças climáticas na agenda municipal de Palmas na gestão (2001-2004). Para isto será adotado o modelo de analise de múltiplos fluxos de Kingdon. Diante disso, definiu-se como objeto empírico deste trabalho a análise da gestão municipal de Palmas nos anos de 2001-2004, pois foi nesta gestão que foi criada sua política municipal de mudanças climáticas. Primeiramente, apresenta-se a discussão entre cidades e mudanças climáticas e qual o papel desempenhado pelas redes transnacionais de municípios neste contexto. Em seguida, é abordada a literatura sobre redes transnacionais, voltando especial atenção a uma dessas redes em específico, o ICLEI, e sua campanha Cidades pela Proteção do Clima (CCP), pois foi a única rede deste gênero que o município de Palmas participou. Na terceira seção, é apresentada a literatura sobre o modelo de análise de políticas públicas de Múltiplos Fluxos. Na quarta seção, o caso analisado é discutido a partir do modelo de Kingdon. E, por fim, são apresentadas as considerações finais, e as reflexões sobre o estudo empreendido.

Espera-se que o estudo de caso sobre Palmas possa contribuir para evidenciar os alcances e limitações dos municípios de médio porte para agir sobre o tema das mudanças climáticas, principalmente compreender como este tema, muitas vezes negligenciado pela sua 
"não urgência", pode subir à agenda de municípios com poucas ameaças ambientais, mas também com poucos recursos e capacidades, como Palmas. Levando-se em conta que dois terços da população brasileira vivem em municípios com menos de 500.000 habitantes (IBGE, 2010), é relevante voltar o olhar para as cidades de pequeno e médio porte.

\section{A Ação Local em Mudanças Climáticas e as Redes Transnacionais}

Há uma vasta literatura a qual compreende a relação entre as cidades e as mudanças climáticas como fundamental. O segundo relatório síntese publicado pelo IPCC, o Fourth Assessment Report, Working Group II (AR4), publicado em 2007, reforçou e legitimou esta discussão, ao mostrar que áreas urbanas são vulneráveis aos impactos da mudança climática (Parry et al., 2007).

Alguns autores afirmam que a esfera local é a mais apropriada à implantação de medidas de mitigação e de adaptação em mudanças climáticas, porque os governos locais estão próximos onde os impactos das mudanças climáticas deverão ocorrer e têm o potencial de empreender ações de mitigação e adaptação a essas mudanças (Puppim de Oliveira, 2009). Robinson e Gore (2005) abordam a relação entre cidades e as mudanças climáticas como sendo baseada em uma complexa balança entre vulnerabilidade e responsabilidade.

A vulnerabilidade reside no fato de que as cidades estão suscetíveis a uma vasta gama de impactos de mudanças climáticas. Por outro lado, a autoridade local possui uma responsabilidade legal que proporciona oportunidades de influenciar muitas atividades que contribuem para as mudanças climáticas e respondem em termos de políticas de mitigação e adaptação (Robinson e Gore, 2005; Bulkeley e Betsill, 2003).

Diversos fatores explicam a vulnerabilidade das cidades aos efeitos das mudanças climáticas. A explicação mais simples reside no fato de que grande parte das atividades humanas que levam ao aquecimento global e contribuem para as transformações ambientais globais, em geral, acontecem em nível local (Wilbanks e Kates, 1999). É nas cidades que ocorrem atividades altamente intensivas em consumo de energia, os que as tornam grandes fontes emissoras de gases geradores de efeito estufa (GEE) (Lankao, 2007a, b). Neste sentido, destacam-se os grandes centros urbanos que agregam um elevado número de indústrias, ampla infraestrutura e contingente populacional.
(Wilbanks et al., 2007; Satterthwaite et al., 2007; Lankao, 2007b; Satterthwaite, 2008).

A responsabilidade identificada por Robinson e Gore (2005), reside no fato de que geralmente o município tem responsabilidade legal para controlar áreas e setores estratégicos que podem influenciar muitas atividades que são tanto fontes críticas de emissões de GEE, quanto instrumentos chave na redução dos riscos climáticos urbanos, tais como a regulamentação do uso do solo, zoneamento, defesa civil, entre outros (Satterthwaite et al., 2007; Bulkeley et al., 2009).

De forma geral, as cidades podem responder às mudanças climáticas por meio de medidas de mitigação, as quais se concentram na redução das emissões líquidas de gases de efeito estufa, e/ ou em medidas de adaptação, as quais se focam na diminuição dos impactos das mudanças climáticas por meio de ajustes e alterações em sistemas sociais e naturais no ambiente urbano (Martins, 2010).

É importante a realização de medidas que incentivam o uso de energias alternativas e renováveis, com baixa emissão de GEE, como uso de bicicleta e transporte público, melhoria da eficiência energética de sistemas urbanos, ações de arborização são exemplos de atividades de mitigação em áreas urbanas. As medidas adaptativas não visam somente o aquecimento global, mas também a variabilidade e os eventos climáticos extremos como ondas de calor, tempestades, enchentes e ciclones tropicais. São atividades mais difíceis de serem definidas e extremamente dependentes do contexto onde elas se aplicam (Martins e Ferreira, 2011).

Além disso, o entendimento de que o município é um agente fundamental nas medidas de mitigação e adaptação às mudanças climáticas baseia-se na suposição de que os governos locais são mais flexíveis e mais responsáveis perante os seus cidadãos do que outros níveis de governança. Neste nível, devido a sua menor dimensão, supõe-se que as decisões podem ser tomadas mais rapidamente do que em nível nacional, possuindo mais flexibilidade e agilidade nas respostas, também motivada pelo contato diário com grupos de interesse, tais como sociedade civil, organizações de base comunitária e os grupos ambientalistas, os quais exercem pressão diariamente (Puppim de Oliveira, 2009). Além das responsabilidades legais já mencionadas, outro fator apontado como relevante é o fato dos governos locais serem capazes de regular e controlar ações de indivíduos e empresas no nível local (Satterthwaite et al., 2007).

Apesar do reconhecimento da importância da gestão do clima pelos municípios, alguns autores chamam a atenção para a necessidade de 
articulações com outras instâncias de governança para que possam estabelecer medidas efetivas, tanto de mitigação quanto de adaptação (Ribeiro, 2008; Satterthwaite et al., 2007).

Nesse sentido, merece ser citado o trabalho de Martins e Ferreira (2010), os quais realizaram uma meta-análise de estudos de casos que envolviam trinta e oito cidades em todo o mundo, buscando compreender quais os fatores que impulsionam e limitam o processo de formulação e implementação de políticas públicas locais tanto de mitigação das mudanças climáticas quanto de adaptação a elas. Como resultado, a participação em redes transnacionais de municípios apareceu como um arranjo de governança que impulsiona a ação local em mudanças climáticas.

As redes transnacionais de municípios, ou TMNs, como são denominadas pelos autores internacionais (fazendo referência à sigla originária do inglês Transnational Municipal Networks) tiveram seu surgimento influenciado por alguns acontecimentos específicos, e são comumente vistos como um resultado concreto da Cúpula do Rio em 1992 (Betsill e Bulkeley, 2006). O aumento da existência deste tipo de redes tem sido marcante nos últimos anos. De acordo com Keiner e Kim (2006), entre os anos de 1982 e 2004, o número de redes de cidades voltadas para a sustentabilidade, aumentaram de oito para 49. Keiner e Kim (2006) fazem referência ao trabalho de Jensen (2004), que apontou que estas redes normalmente visam a três objetivos: a) a aprendizagem (por exemplo, a troca de conhecimentos, experiências, inovação, benchmarking, etc.); b) o lobby (por exemplo, atuando como centros de conhecimento e formuladores de políticas); c) o branding (por exemplo, a missão desta rede dá aos participantes uma imagem "verde" ou de amiga do meio ambiente) (Jensen, 2004 apud Keiner e Kim, 2006). De acordo com Kern e Alber (2008: 14, tradução nossa):

[...] os objetivos das redes transnacionais de cidades incluem a transferência de melhores práticas, a aprendizagem entre os seus membros em âmbito doméstico e no exterior, e a representação dos interesses dos seus membros no âmbito nacional, europeu e internacional do sistema multinível.

Assim, para que o município possa gerir uma questão tão complexa, como a climática, as redes transnacionais, apareceriam como uma ferramenta de governança que o município poderia utilizar-se para conseguir agir localmente sobre um problema global. Neste sentido, tais redes operam como interlocutoras entre o governo local e o meio internacional, procurando advogar perante os governos nacionais, organizações regionais e os diversos organismos multilaterais e instituições que fazem parte do regime internacional de mudanças climáticas, objetivando reforçar o papel dos governos locais na temática. Além do papel de advocacy, tais redes visam reforçar a capacidade do governo local de lidar com o tema, a partir do intercâmbio e disseminação de boas práticas que caracterizam o trabalho em rede.

\section{ICLEl e a Campanha Cidades pela Proteção do Clima (CCP)}

O Local Governments for Sustainability (ICLEI) é uma das maiores redes transnacionais que atuam na temática ambiental (Betsill e Bulkeley, 2006). A organização foi fundada em 1990, pela International Union of Local Authorities (UILA) e o United Nations Environment Programme (UNEP), para representar os governos locais internacionalmente quanto a questão ambiental (Betsill e Bulkeley, 2004).

Atualmente, são membros do ICLEI, mais de 1100 municípios e associações em todo o mundo. De acordo com a organização:

Na América Latina, 23 governos locais são membros ativos; e mais de 100 assumiram o compromisso de executar o desenvolvimento sustentável através das campanhas e programas do ICLEI-LACS.” (ICLEI, 2013).

No Brasil, são 26 membros, sendo que apenas 3 não são governos locais, o Estado de São Paulo, o Estado de Minas Gerais e o IPPLAN (Instituto de Pesquisa, Administração e Planejamento de São José dos Campos) (ICLEI, 2013).

O ICLEI lançou campanhas nacionais, a partir do ano de 2002, em diversos países e campanhas regionais foram lançadas na Europa, Ásia, e América Latina (Betsill e Bulkeley, 2004). Na América Latina, a campanha CCP iniciou-se em 1998, no México; e a partir de 2001, a campanha estendeu-se para a América do Sul, com apoio financeiro da Agência Canadense de Desenvolvimento Internacional (CIDA). Brasil, Argentina e Chile foram os países participantes (ICLEI, 2013). No Brasil, participaram da campanha CCP as seguintes cidades: Belo Horizonte, Betim, Goiânia, Palmas, Porto Alegre, Rio de Janeiro, São Paulo e Volta Redonda.

Dentre os objetivos estabelecidos para a campanha, estavam: (1) O reforço dos compromissos locais para reduzir as emissões urbanas de gases de efeito estufa; (2) A divulgação de ferramentas de gestão e planejamento para facilitar o desenvolvimento da relação custo benefício das políticas de redução de $\mathrm{CO} 2$; (3) A pesquisa e desenvolvimento de 
melhores práticas, e municípios modelo, os quais deveriam servir de referência; e (4) O reforço dos laços nacionais e internacionais para que as ações a nível municipal estejam incluídas nos planos de ação nacional e nas deliberações internacionais (ICLEI, 1993 apud Lindseth, 2004).

Uma vez que adere a campanha, o governo local deve passar por cinco etapas. As etapas ou marcos compõem-se de uma metodologia a fim de ajudar os governos locais para entender como as decisões municipais afetam o uso da energia, e como reduções no consumo de energia podem mitigar as mudanças climáticas melhorando a qualidade de vida (Lindseth, 2004), incluem-se: a construção de um inventário de padrões de emissões; a adoção de metas de redução de emissões; o desenvolvimento de um Plano de Ação Local; a execução de políticas e medidas; e o monitoramento dos resultados (Betsill e Bulkeley, 2004).

Para concluir as cinco etapas, as cidades recebem assistência técnica e treinamento por parte do ICLEI, na forma de workshops, financiamento para realizar a análise de emissões e um software que foi especialmente concebido para possibilitar às cidades o cálculo de suas emissões passadas e atuais, a avaliação de opções para reduzir as emissões e o monitoramento dos efeitos das medidas de redução em termos de economia de custos e de emissões de GEE (Betsill, 2001).

Além do ICLEI, existem inúmeras redes de municípios que trabalham em prol da proteção climática. Entretanto, a mera existência de arranjos de governança como as redes transnacionais que apoiam a ação local, não constituem condição suficiente para explicar porque alguns municípios agem em torno da problemática do clima enquanto outros não. Além disso, a existência de vulnerabilidade por parte dos municípios e a sua responsabilidade legal para regular os setores que são estratégicos para a proteção climática também não garante que o município atue sob a questão, quando não há nenhum constrangimento legal que o condicione a adotar políticas deste tipo.

Desta forma, chama-se a atenção para o fato de que é importante compreender quais os mecanismos subjacentes à entrada do tema na agenda municipal, ou seja, porque alguns municípios estabelecem políticas publicas em prol da proteção climática e outros não? Ou porque os municípios estabelecem programas e políticas que em momentos posteriores são abandonados? Para que se possa compreender os mecanismos de formação da agenda governamental e o processo de formulação de políticas públicas, será abordado a seguir o modelo de Múltiplos Fluxos.

\section{O Modelo de Múltiplos Fluxos e a Formulação de Políticas Públicas}

Vários são os modelos que podem ser utilizados para a análise de políticas públicas. O modelo de Múltiplos Fluxos de Kingdon, na visão de John (1998) é um modelo mais completo na medida em que ao tratar de variáveis diversas - os agentes, ideias, instituições e processos externos - no processo de formulação de políticas públicas, tende a ser uma abordagem mais integradora (John, 1998).

O modelo de múltiplos fluxos é o mais apropriado para a análise aqui empreendida uma vez que o modelo foca-se no estudo do processo de formulação da agenda governamental. Neste sentido, procura compreender porque um tema passa a chamar a atenção dos formuladores de políticas públicas e ascende a agenda, e porque ao contrário, temas podem deixar a agenda.

O modelo de Múltiplos Fluxos tem como ponto de partida o modelo de Garbage Can, desenvolvido por Cohen, March e Olsen. Neste modelo, as organizações são compreendidas como anarquias organizadas, cujas escolhas estão presentes em uma "lata de lixo", e que vão sendo reutilizadas pelos participantes na medida em que surgem (Cohen; March; Olsen, 1972, apud Souza, 2006).

Em seu modelo, Kingdon analisou o governo federal norte americano, em uma extensa pesquisa empírica, sendo entrevistados diversos atores no setor de saúde e transporte entre 1976 e 1979. Neste sentido, o modelo de Múltiplos Fluxos indica que o processo de formulação da agenda, é um processo altamente competitivo e que mudanças na agenda ocorrem quando da convergência de três fluxos, os quais possuem sua dinâmica própria e que caminham relativamente independentes: o fluxo político (politics stream), o de soluções (policy stream) e o de problemas (problem stream) (Kingdon, 2011). Além da dinâmica dos três fluxos, o autor também ressalta a importância dos diferentes agentes no processo de formulação da agenda (Kingdon, 2011)

Para que se compreenda o mecanismo subjacente à mudança na agenda, é necessário compreender primeiramente o fluxo de problemas. Desta forma, o autor aponta a importância de se compreender a diferença do que ele chama de questões (conditions) de problemas. Uma questão é uma situação social percebida, mas que não necessariamente desperta uma ação em contrapartida. Esta apenas se configurará como problema, quando os formuladores acreditarem que devem agir sobre ela (Kingdon, 2011).

Kingdon (2011) aponta três mecanismos que podem contribuir para chamar a atenção dos formuladores, contribuindo assim para que uma 
questão seja entendida como um problema: os indicadores, eventos focais e feedback. Os indicadores podem revelar a existência de uma situação e sua magnitude. Os eventos focais, como crises, desastres ou símbolos ajudam a concentrar a atenção em determinado assunto, entretanto, não são suficientes para por si só elevarem um assunto à agenda, e o terceiro mecanismo constitui-se nos feedbacks sobre programas em desenvolvimento no governo. Entretanto, o autor ressalta que a percepção de um problema envolve um elemento interpretativo por parte dos formuladores. Assim, o modo como um problema é formulado é uma questão de estratégia política que pode determinar o sucesso de uma questão no processo altamente competitivo de agenda setting (Kingdon, 2011).

No modelo de Múltiplos Fluxos, da mesma forma que questões ganham notoriedade e se tornam problemas, passando a compor a agenda governamental, por outro lado há problemas que perdem importância e podem deixar a agenda governamental. Isto ocorre porque podem simplesmente perder a importância, ou deixar de ser entendidos como problemas. Pode ocorrer também o fato de o governo pensar já ter resolvido o problema com ações simples, ou ainda quando ocorre o descrédito a determinado tipo de ação, devido a um fracasso de um programa ou política governamental (Kingdon, 2011).

O segundo fluxo, o fluxo de soluções, ou policy stream "[...] ocorre sem estar necessariamente relacionado à percepção do problema [...]" (Calmon e Marchesini, 2007: 8). As alternativas são geradas nas policy communities, ou comunidades geradoras de alternativas. Nelas são geradas as ideias a respeito de soluções, que flutuam em "um caldo primitivo" de políticas, que semelhante ao processo de seleção natural, adaptam-se e combinam umas com as outras, ou permanecem intactas ou ainda são descartadas. Assim há uma seleção de alternativas, comparável à seleção natural e, desta forma, um numero menor de alternativas chega ao conhecimento dos decisores. Então, as alternativas que se mostrem viáveis do ponto de vista técnico e que apresentem custos viáveis geralmente sobrevivem. A partir daí tais alternativas passam a ser difundidas, não de uma forma automática, mas sim por uma dinâmica de persuasão em que os indivíduos passam a defender a ideia não só para as comunidades políticas como também para o publico em geral, construindo progressivamente a aceitação da ideia (Kingdon, 2011).

Entretanto, a expressão comunidade, não implica uma coesão. Há fragmentação dentro da comunidade. Algumas são extremamente coesas e herméticas, outras são fragmentadas e mais diversas. Por exemplo, o sistema de saúde americano, é um exemplo de uma comunidade muito menos fragmentada do que a de transportes por exemplo. Isto porque, os indivíduos envolvidos nesta comunidade, apesar de diferentes (médicos, pesquisadores, especialistas em RH entre outros) em grande medida lidam com o mesmo problema, a saúde das pessoas e o pagamento por serviços médicos (Kingdon, 2011).

O terceiro fluxo, o político, é composto por elementos tais como: a opinião pública, grupos de pressão, resultados eleitorais, distribuições partidárias ou ideológicas no Congresso e mudanças na administração (Kingdon, 2011). Nesse fluxo, três elementos são influentes sobre a agenda governamental: o "humor" nacional (national moodino), as forcas políticas organizadas, e as mudanças dentro do próprio governo. O humor nacional, "cria uma espécie de 'solo fértil' para algumas ideias germinarem" (Capella, 2007: 29). Assim, o humor favorável pode incentivar a promoção de algumas questões e ao mesmo tempo desestimular a promoção de outras (Capella, 2007).

As forças políticas organizadas são exercidas principalmente pelos grupos de pressão. Os decisores tendem a seguir a mesma posição assumida pelas forcas políticas quando os grupos se encontram em uma posição de consenso. E quando há conflito de posições entre grupos, os decisores tendem a avaliar o balanço de forças em disputa para, a partir de então, decidirem sobre sua própria posição considerando a intensidade da comunicação de cada parte, e os recursos possuídos por cada grupo (Kingdon, 2011).

Finalmente, as mudanças dentro do próprio governo também tem impacto na agenda governamental e incluem mudanças de pessoas em posições estratégicas, mudanças de gestão, na chefia de órgãos e empresas públicas, e, mudanças na composição do Congresso. Kingdon (2011) afirma que o início de um novo governo é o momento mais propicio para mudanças na agenda. O impacto na agenda governamental se deve ao fato de que as mudanças podem desencadear a introdução de novos temas na agenda, assim, como a restrição de outros (Kingdon, 2011).

Os três fluxos mencionados possuem sua dinâmica própria e caminham com relativa independência e por vezes se convergem gerando uma oportunidade de mudança na agenda, a qual Kingdon denomina de janela de oportunidade, ou windows opportunity. Que se constituem em momentos transitórios, podendo ocorrer a abertura de "janelas" em determinados momentos bem como o seu fechamento em outros (Kingdon, 2011). É neste momento que uma condição consegue atrair a atenção dos formuladores de 
políticas públicas e é também no mesmo momento que há mudanças no fluxo político as quais permitem mudanças na agenda. E, assim, os formuladores passam a procurar alternativas para os problemas no fluxo de soluções. Desta forma, Kingdon aponta que a abertura de janelas de oportunidade são influenciadas sobretudo pelo fluxo de problemas e pelo fluxo político (Capella, 2007).

Entretanto, para que haja o encontro dos três fluxos, a figura do empreendedor de políticas ou policy entrepreneur é fundamental, pois sem ele a união entre os fluxos pode não ocorrer. Isto, porque tais indivíduos atuam "[...] unindo soluções a problemas; propostas a momentos políticos, eventos políticos a problemas [...]" (Capella, 2007: 31). Estes indivíduos estão dispostos a investir em uma ideia, podendo fazer parte do governo ou não. Geralmente são especialistas em determinada questão e são hábeis em representar ideias de outros indivíduos ou grupos, ou ainda podem desfrutar de uma posição de autoridade dentro do processo decisório, o que proporciona receptividade a suas ideias. Alem disso, estão dispostos a investir diversos tipos de recursos em troca de futuros ganhos na forma de benefícios materiais (Capella, 2007).

Além da dinâmica dos fluxos políticos, os atores envolvidos no processo também são determinantes para as mudanças na agenda. Kingdon (2011) apresenta a influencia de atores governamentais (a "administração", os servidores de carreira, os deputados e senadores e seus assessores) e não governamentais (grupos de interesse, acadêmicos, pesquisadores e consultores, opinião publica, partidos políticos). Sendo que os atores governamentais possuem mais recursos para interferir na formulação das políticas publicas que os não-governamentais. Dentre o primeiro grupo. Os atores governamentais, a "administração" inclui o presidente, sua assessoria e seus demais cargos cuja indicação cabe exclusivamente a ele. O presidente é o ator mais importante no fluxo político, exercendo um papel dominante na formulação da agenda, pois detém recursos institucionais, organizacionais e recursos de comando da atenção. Entretanto, como não tem controle sobre o fluxo de alternativas, não pode determinar o resultado de uma política (Kingdon, 2011).

A assessoria do presidente por sua vez, cumpre um papel maior no fluxo de soluções ao apontar as alternativas possíveis. Os ocupantes de cargos de confiança, como os ministros, por exemplo, assim como os assessores representam um papel maior na geração de alternativas, neste caso, na difusão de ideias. Os servidores de carreira também são destacados como importantes atores governamentais na medida em que possuem um conhecimento especializado proporcionado pela estabilidade no serviço que permite influir na geração de alternativas (Kingdon, 2011).

O autor também ressalta a importância poder legislativo a nível nacional, que segundo o ele, é tão importante quanto o poder executivo no processo de formulação de políticas públicas. Neste sentido os deputados e senadores cumprem um papel importante, segundo Kingdon (2011), eles são um dos poucos atores que exercem influencia tanto na formação da agenda, quanto na formulação de alternativas. Os congressistas agem por vários motivos (como na satisfação dos eleitores, obtenção de poder político, diferenciação dos demais congressistas), o que os leva a muitas vezes defender mudanças na agenda, visando cumprir com tais objetivos (Kingdon, 2011).

No modelo de Kingdon atribui-se um papel importante aos assessores e do corpo de técnicos do Congresso, em especial os que atuam em comissões, os quais constituem um corpo de especialistas em determinada matéria, fazendo com que esses atores desempenhem um papel importante na geração de alternativas para os problemas, bem como na definição da forma de encaminhamento das propostas (Kingdon, 2011).

No modelo também há destaque para os atores não governamentais, os quais também exercem papel relevante na formulação da agenda. Dentre esses, os mais relevantes seriam os grupos de interesse, seguido pelos acadêmicos, pesquisadores e consultores. Kingdon (2011) destaca também a importância dos atores relacionados com o processo eleitoral. A mídia aparece como pouco influente no processo de formação da agenda de políticas públicas, uma vez que atua mais no sentido de chamar a atenção para problemas já existentes ou políticas públicas já formuladas e em andamento. A opinião publica também tem importância uma vez que pode promover ou bloquear determinadas propostas (Kingdon, 2011).

A seguir será discutido como a questão das mudanças climáticas ascendeu à agenda municipal de Palmas, fazendo como que o município fosse o primeiro do País a possuir uma lei especifica para regular o tema. Procuraremos compreender o comportamento dos três fluxos ao longo da gestão municipal no período de (2001-2004) e o comportamento dos diversos atores que influíram para que o tema ganhasse relevância. 


\section{Palmas e sua Política de Mudanças Climáticas e a Campanha CCP do ICLEl: como 0 Tema Ascendeu a Agenda Municipal?}

De acordo com o modelo de múltiplos fluxos, tanto a mudança "de governo" como "dentro do governo" podem desencadear mudanças na agenda. O início de um novo governo é, segundo Kingdon (2011), o momento mais propício para que novos temas sejam introduzidos ou ocorra a restrição de outros na agenda governamental. No caso de Palmas, o início do novo governo municipal em 2001, desencadeou algumas mudanças que permitiram que o tema da proteção do clima adentrasse a agenda. Prova disso está na criação, logo no início do novo governo, em junho de 2011, de instituições e mecanismos para lidar com a questão ambiental, o que já indicava uma pré-disposição para a atuação em torno dessa temática.

Foi o caso da Política Ambiental do Município instituída pela Lei $\mathrm{n}^{\circ} 1.011$ de 04 de junho de 2001 . A referida lei criou o Sistema Municipal de Meio Ambiente (SIMA) dos quais faziam parte além a Agência de Meio Ambiente e Turismo (AMATUR), o Conselho Municipal de Meio Ambiente (CMMA), e o Fundo Municipal de Meio Ambiente (FMMA) instrumento econômico cuja gestão era realizada pela AMATUR, e que tinha como objetivos financiar projetos, pesquisas e demais atividades que visassem o uso racional e sustentável dos recursos ambientais. Além disso, objetivava o direcionamento dos recursos às ações de controle, fiscalização, defesa e recuperação do meio ambiente.

Além disso, outros programas e projetos forma implementados relacionados a questão ambiental, como o projeto "Reluz" que objetivava a modernização e melhoria da eficiência energética de sistemas de iluminação pública, por meio da substituição de 16.300 lâmpadas convencionais, por outras mais econômicas e a instalação do aterro sanitário de Palmas, que possuía um sistema de tratamento de chorume (líquido produzido pela decomposição da matéria orgânica) (Piva, 2007).

Tais medidas evidenciam o lugar de destaque que as questões ambientais ocupavam na agenda da administração pública. Tal fato pode ser explicado pela aproximação da então prefeita e um dos vereadores, com atuação na temática ambiental, formando uma "policy community". Desta forma podemos dizer, que o fluxo politico a época criou um "solo fértil" para que a temática da proteção do clima adentrasse a agenda municipal ou mesmo que as mudanças climáticas fossem percebidas como um problema, pois como afirma Kingdon (2011), a percepção de um problema envolve além de indicadores, eventos focais e feedback, um elemento interpretativo por parte dos formuladores de políticas públicas.

No fluxo de problemas, a cidade de Palmas não possui grandes ameaças ambientais como São Paulo e Rio de Janeiro, porém o município apresenta desde sua constituição, grandes vazios urbanos que contribuem para que a cidade possua o mais elevado custo per capita de urbanização do País, estimado no ano de 2005 (Bazolli, 2009). Em 2002, a cidade apresentava um elevado índice de área verde por habitante, aproximadamente $280 \mathrm{~m}^{2}$, decorrente em parte das características de arborização previstas no seu plano diretor, e também pelos grandes vazios urbanos característicos do seu processo de ocupação (PSCUP, 2002).

Neste caso, a existência de grandes áreas verdes, tornava ainda mais custoso a manutenção dessas áreas e a gestão urbana do município. Outro fator que atraia a atenção dos gestores a época era a ameaça provocada pelas queimadas, que além dos prejuízos decorrentes da emissão de $\mathrm{CO} 2$, ainda traz outras consequências negativas, como a redução da biodiversidade de fauna e flora local (PSCUP, 2002).

Paralelamente ao fluxo político e ao fluxo de problemas, eram geradas alternativas (fluxo de soluções) que envolviam a temática ambiental. Em 2002, foi elaborado o primeiro projeto de sequestro de carbono em área urbana do Brasil, o qual apresentou uma solução para o problema do alto custo de manutenção das áreas verdes da cidade, e que teve estreita relação com a criação da lei municipal de mudanças climáticas e foi fundamental para que o município pudesse ser aceito na Campanha Cidades pela Proteção do Clima do ICLEI. O projeto foi criado em junho de 2002, e contou com a participação de diversas instituições, dentre elas o Ministério do Meio Ambiente (MMA) e o Banco Mundial (BIRD) e o Instituto Ecológica, seu principal objetivo residia na absorção de dióxido de carbono (CO2) da atmosfera, a partir da adoção do Mecanismo de Desenvolvimento Limpo (MDL), e a comercialização dos créditos de carbono através da prática do conceito do "carbono social" (PSCUP, 2002).

O Projeto abrangeria as áreas pertencentes ao Poder Público Municipal, que se encontrava em avançado estado de degradação devido principalmente ao desmatamento ilegal decorrente da pressão para a implantação da cidade (PSCUP, 2002). Tais áreas seriam transformadas, no decorrer da implementação do projeto em Unidades de Conservação Municipais. No próprio texto do projeto estava estabelecido que os recursos oriundos da venda de créditos de carbono via Mecanismo de Desenvolvimento Limpo (MDL) seriam 
investidos em quatro áreas: a) projetos sociais, que iam desde a educação ambiental, até ações envolvendo a promoção do turismo; b) redução das emissões de gases de efeito estufa, por meio da implantação de parques e jardins e conservação e regeneração de áreas verdes degradadas; c) fortalecimento do sistema de monitoramento ambiental; d) capacitação da comunidade para projetos de geração de renda (PSCUP, 2002).

Assim, logo no início da gestão municipal (20012004), o fluxo político favorecia mudanças na agenda na direção da incorporação da temática ambiental e, consequentemente das mudanças climáticas. No fluxo de problemas, a gestão das áreas verdes, as queimadas e os grandes vazios urbanos eram questões que se faziam presentes e foram percebidas pelos gestores da época. Ao mesmo tempo, soluções estavam sendo desenhadas, como o projeto de sequestro de carbono.

Entretanto para que pudesse ocorrer a abertura de uma "janela de oportunidade" como expõe Kingdon (2011), para que o tema das mudanças climáticas fosse inserido na agenda, além da convergência dos três fluxos, foi fundamental a presença de um empreendedor de políticas (Kingdom, 2011). Neste caso, este papel foi cumprido pelo então Presidente do Instituto Ecológica.

Além da participação no desenho do Projeto de Sequestro de Carbono, o então Presidente do Instituto, foi responsável pela articulação com o ICLEI, realizando uma aproximação, um primeiro contato entre a rede e a cidade. Sobre essa articulação, o mesmo afirmou que:

O ICLEI foi uma articulação que nós ajudamos a fazer no sentido de colocar Palmas dentro de uma dimensão mais ampla que o contexto regional e nacional, então a ideia de Palmas entrar no ICLEI era de Palmas passar a ter um status como outras capitais no mundo todo e com isso trocar experiências.

A participação de Palmas na Campanha CCP do ICLEI esteve fortemente vinculada ao projeto de sequestro de carbono que já havia sido elaborado, por iniciativa da prefeitura. Neste sentido, de acordo com o então presidente da extinta AMATUR: “[...] como o projeto de sequestro de carbono era muito atraente, o ICLEI abriu uma exceção e incluiu Palmas e passaram a ser dez cidades". O gerente de projetos da extinta AMATUR, segue na mesma direção: “[...] para que nós tornássemos digamos... elegíveis na campanha, o projeto de sequestro de carbono foi muito preponderante".

Ao mesmo tempo em que o projeto de sequestro de carbono atraiu a atenção do ICLEI e possibilitou a inclusão de Palmas na campanha CCP, a prefeitura via nesse engajamento uma possibilidade de implementar o projeto inovador. Isto porque um projeto de mitigação dos gases causadores do efeito estufa via MDL, como era o caso, é um tipo de cooperação transnacional que envolve um país financiador e um país sede (PSCUP, 2002).

Assim, além da conferir legitimidade ao projeto, a participação no ICLEI era entendida como uma forma de divulgá-lo e atrair a atenção de instituições financiadoras de outros países, uma vez que o ICLEI, por meio de sua expertise na área poderia orientar a prefeitura sobre as fontes de obtenção de recursos financeiros. Tal fato fica evidente na fala do então gerente de meio ambiente da extinta AMATUR:

[...] o ICLEI é essa mola propulsora, ele vai buscar o recurso. A organização em si não tem o recurso, mas ela vai buscar onde existe".

Da mesma forma, a criação da lei que instituiu a Política Municipal de Mudanças em maio de 2002 aparece ligada à viabilização do projeto de sequestro de carbono. A mesma era vista, como relatou o ex-presidente da extinta AMATUR, como um instrumento "para vender, no bom sentido, um projeto de sequestro de carbono [...]". Isto fica bastante claro ao se analisar o texto da lei, o qual se restringe a regulação das ações do município com relação a projetos nas áreas florestal e energética, autorizando a AMATUR a negociar e comercializar os créditos de carbono fixados nas áreas verdes especiais e contratar assessoria técnica para orientação das diretrizes dos projetos na área de mudanças climáticas (Palmas, 2003).

Dessa forma, a criação da lei que instituiu a Política Municipal de Mudanças Climáticas já estava prevista no texto do Projeto de Sequestro de Carbono como uma das ações a serem desenvolvidas, pois se fazia necessário regulamentar as ações do município em projetos desta natureza. $\mathrm{O}$ projeto de lei foi proposto pelo executivo em novembro de 2002 e sancionado em maio de 2003, o que nos leva a crer que houve relativa facilidade na instância legislativa. Tal fato pode ser explicado pelo caráter regulatório da lei, a qual diferentemente das políticas municipais de São Paulo e Rio de Janeiro não fixava metas de redução de emissão de CO2.

A motivação para a criação da lei de mudanças climáticas partiu da prefeitura de Palmas, antes mesmo da adesão à rede. Em relação à participação do ICLEI na formulação da lei, a maioria dos entrevistados não a destacou como relevante. Assim, em Palmas, ao contrário de São Paulo, o engajamento do ICLEI não ocorreu formalmente para o desenho institucional da Lei. 
Por outro lado em Palmas, o software e a assessoria técnica prestada pelo ICLEI foram fundamentais para a elaboração de um inventário de emissões, o que não ocorreu no caso dos municípios de São Paulo e Rio de Janeiro que estabeleceram parcerias com Universidades e Centros de Pesquisa para a elaboração de seus inventários de emissões, não dependendo fundamentalmente de ferramentas proporcionadas pelo ICLEI (Furriela, 2011; Puppim de Oliveira, 2009), o que reforçou as políticas já em andamento no município.

Após a realização do inventário de emissões, a terceira etapa da campanha era a realização de um Plano de Ação com o estabelecimento de uma meta de redução de GEE e o estabelecimento de políticas e medidas para se alcançar esse objetivo. O município apresentou seu plano de ação durante o $\mathrm{V}$ workshop da campanha CCP, em outubro de 2004, logo após as eleições municipais.

O Plano de Ação previa para o ano de 2011 uma meta de redução de $20 \%$ das emissões de gases causadores do efeito estufa com relação ao ano de 2001 (Piva, 2007).

No início da gestão 2005-2008, a organização e a estrutura administrativa do poder executivo municipal foram alteradas mediante a Lei $\mathrm{n}^{\mathrm{o}} 1.365$ de março de 2005. Com a nova estrutura, a AMATUR foi extinta, e a gestão ambiental passou a ser de responsabilidade da Secretaria de Meio Ambiente e Turismo, órgão da administração direta.

$\mathrm{Na}$ nova gestão, o projeto de sequestro de carbono não chegou a ser implementado, e Palmas se desligou do ICLEI, e consequentemente, da participação na campanha CCP. Ao ser indagado se tinha conhecimento das ações desenvolvidas no âmbito da participação na CCP, o então Prefeito, que cumpria seu segundo mandato (2009-2012), afirmou que: Conhecimento nós tivemos, o que eu achei estranho é que nada ficou registrado na Prefeitura [...] mas não herdamos isso de forma materializada. O então prefeito alegou ter conhecimento do Projeto de Sequestro de Carbono apenas pela mídia. Segundo o então prefeito, não havia documentos na prefeitura sobre o projeto e nem mesmo da associação de Palmas ao ICLEI. O Secretário de Meio Ambiente, empossado em 2005 na recém-criada Secretaria de Meio Ambiente e Turismo, corrobora a afirmação do então prefeito. Em entrevista, no ano de 2007, a um jornal local, o mesmo afirmou que:

[...] quando assumimos a secretaria não havia nenhum registro de projeto tecnicamente construído para sequestro de carbono de floresta urbana e nem de conhecimento da comissão interministerial de Mudança Global do Clima [...] (Coelho, 2007).

Entretanto, o então prefeito quando indagado sobre as possíveis ações desenvolvidas no âmbito da Política Municipal de Mudanças Climáticas durante seus dois mandatos (2005-2008 e 2009-2012), o mesmo afirmou que, devido ao próprio Protocolo de Kyoto, não "ter avançado muito" a política municipal não teve um "dinamismo". Ainda segundo o então prefeito, "buscava-se dentro das normativas do tratado, agora as ações que o município tem desenvolvido eu penso que vão muito além do que foi estabelecido nessas metas". Ao afirmar que: "buscava-se dentro das normativas do tratado (Kyoto)" o então prefeito faz alusão ao projeto de sequestro de carbono. Entretanto, segundo ele, as ações que o município desenvolveu sob sua gestão, são muito mais amplas e vão além de medidas de mitigação e redução das emissões de dióxido de carbono por meio do sequestro de carbono.

Desta forma, a agenda climática do município representada pela associação do município ao ICLEI, o projeto de sequestro de carbono e a Política Municipal de Mudanças Climáticas aparecem na fala da maioria dos entrevistados como ações estratégicas de um mesmo projeto, o qual estava associado a um grupo político específico. Por outro lado, não se pode avaliar se caso a cidade continuasse participando da campanha CCP do ICLEI, a implantação das políticas desenhadas em seu Plano de Ação seriam possíveis, ou mesmo efetivas, devido às próprias dificuldades inerentes à implantação de medidas de mitigação pelos municípios. Como era o primeiro projeto deste tipo no Brasil, as próprias barreiras legais-institucionais dificultariam a implementação desse projeto mesmo que houvesse vontade política nos gestores municipais de dar continuidade ao mesmo. No próprio texto do projeto constava que seria requerida ao governo brasileiro alguma forma de aprovação para transação de créditos de carbono pela AMATUR (PSCUP, 2002).

Entretanto, fica claro que a descontinuidade politica provocou um "turnover" que retirou a questão climática da agenda do município. Fica evidente a fragilidade da ação climática por municípios de médio porte como Palmas se comparado a São Paulo, cuja agenda climática persistiu mesmo passando pelos diferentes governos (Back, 2012). Isto porque em Palmas o problema das mudanças climáticas foi interpretado pelos gestores mais como uma oportunidade de consecução recursos financeiros do que como um problema que demandasse ações urgentes. 


\section{Considerações Finais}

Muito tem se discutido sobre a questão das mudanças climáticas e a importância da atuação do município na questão, especialmente devido à vulnerabilidade das cidades aos impactos advindos das mudanças climáticas, e também ao sua responsabilidade sobre a regulação de setores estratégicos que podem influenciar muitas atividades que são tanto fontes críticas de emissões de GEE, quanto instrumentos chave na redução dos riscos climáticos urbanos, tais como a regulamentação do uso do solo, zoneamento, defesa civil, entre outros (Satterthwaite et al., 2007; Bulkeley et al., 2009).

Neste sentido, as redes transnacionais de municípios aparecem como arranjos de governança que impulsionam a ação local em mudanças climáticas. Entretanto, quando não há um ordenamento jurídico nacional que determine a ação do município sobre o tema, torna-se fundamental compreender o que determina que alguns municípios estabeleçam políticas e outros simplesmente ignorem o problema, ou ainda, porque muitas vezes programas e políticas deste tipo não apresentam continuidade.

$\mathrm{Na}$ análise da formação da agenda governamental no caso de Palmas, a partir do modelo de múltiplos fluxos, pode-se perceber a questão da proteção do clima encontrou um fluxo político (mudança de governo e criação de instituições voltadas à questão ambiental) e de problemas (grandes vazios urbanos, ocorrência de queimadas e alto custo de urbanização) favoráveis para que o tema adentrasse a agenda no início da gestão municipal em 2001. No fluxo de soluções, um projeto de sequestro de carbono foi desenhado com a participação do Instituto Ecológica, organização não governamental que possui larga expertise em assuntos relativos às mudanças climáticas. Entretanto, somente a existência de um fluxo político favorável e a percepção dos problemas não seria condição suficiente para que o tema ascendesse à agenda, sendo necessária a atuação de um empreendedor de políticas. No caso analisado essa função foi desempenhada pelo presidente do Instituto Ecológica que além de ter participado do fluxo de soluções, no desenho do projeto de sequestro de carbono, atuou fazendo a articulação entre os gestores municipais e o ICLEI.

Assim, ao contrario de São Paulo, entende-se que a participação do ICLEI não foi fundamental para estimular que o tema adentrasse à agenda municipal, mas reforçou a importância do tema e contribuiu para criar capacidade local para atuar sobre a problemática. Entretanto, fica claro que a descontinuidade politica provocou um "turnover" que retirou a questão climática da agenda do município, o que segundo
Kingdom (2011) é bastante previsível, pois a mudança de governo é um momento tanto para a inserção de novos temas na agenda, quanto a retirada de outros.

Neste sentido, é patente a diferença das ameaças ambientais de cidades médias como Palmas e megacidades como São Paulo e Rio de Janeiro, por exemplo, o que talvez determine a fragilidade da permanência da problemática na agenda governamental por um longo período de tempo em detrimento de temas talvez considerados "mais urgentes", como saúde e educação, por exemplo. Considerando que há várias leis tanto nos estados quanto nos município brasileiros regulamentadas ou em tramitação sobre mudanças climáticas faz-se necessário a realização de estudos para compreender como a Política Nacional sobre Mudança do Clima, pode colaborar para uma ação mais assertivas e em longo prazo dos governos locais em questões climáticas.

\section{Referências}

Back, Adalberto Gregório. 2012. Agenda climática do município de São Paulo: contribuição de redes transnacionais de governos locais. Teoria \& Pesquisa: Revista de Ciência Política, 21(2): 97-107. http:// dx.doi.org/10.4322/tp.2012.014

Bazolli, João Aparecido. 2009. Os efeitos dos Vazios Urbanos no Custo de Urbanização da Cidade de Palmas - TO. Estudos Geográficos Unesp, 7(1): 103-123. Disponível em: <http://www.periodicos. rc.biblioteca.unesp.br/index.php/estgeo/article/ view/541>.

Betsill, Michel Merrill. 2001. Mitigating Climate Change in US Cities: opportunities and obstacles. Local Environment, 6(4): 393-406. http://dx.doi. org/10.1080/13549830120091699

Betsill, Michele Merrill e Bulkeley, Harriet. 2006. Cities and the multilevel governance of global climate change. Global Governance, 12 (2): 141-159.

Betsill, Michele Merrill e Bulkeley, Harriet. 2004. Transnational Networks and Global Environmental Governance: The Cities for Climate Protection Program. International Studies Quarterly, 48: 471-493. http:// dx.doi.org/10.1111/j.0020-8833.2004.00310.x

Bulkeley, Harriet e Betsill, Michele Merrill. 2003. Cities and Climate Change: Urban Sustainability and Global Environmental Governance. London: Routledge.

Bulkeley, Harriet; Schroeder, Heike; Janda, Katy; Zhao, Jimin; Armstrong, Andrea; Chu, Shu Yi e Ghosh, Shibani. 2009. Cities and Climate Change: The role of institutions, governance and urban planning. Marseille, World Bank 5th Urban Symposium on Climate Change. p. 5-28. 
Calmon, Paulo Du Pin e Marchesini, Marcelo. 2007. Análise de Políticas Públicas no Brasil: Estudos sobre a Formação da Agenda Governamental. Brasília, DF. XXXI Encontro da Associação Nacional de Pós-Graduação e Pesquisa em Administração.

Capella, Ana Claudia. 2007. Perspectivas teóricas sobre o processo de formulação de políticas públicas. In G. Hochman, M. Arretche e E. Marques (org.), Políticas Públicas no Brasil. Rio de Janeiro: Editora Fiocruz, p. 87-122.

Coelho, Umberto Salvador. 2007. Aquecimento global e mercado econológico incipiente no Tocantins. Jornal Conexão Tocantins, Palmas, $30 \mathrm{dez}$. (on-line). Disponível em: <http://conexaoto.com.br/2007/12/30/ aquecimento-global-e-mercado-econologicoincipiente-no-tocantins>. Acesso em: 3 jun. 2011.

Confederação Nacional de Municípios - CNM. 2009. Diagnóstico da Municipalização do Meio Ambiente no Brasil. Disponível em: <http://www.cnm.org. br/index.php?option $=$ com_docman\&task=cat_ view\&gid=102\&Itemid=4>. Acesso em: 27 out. 2011.

Furriela, Rachel Biderman. 2011. Limites e alcances da participação pública na implementação de políticas subnacionais em mudanças climáticas e o município de São Paulo. Tese (Doutorado), Escola de Administração de Empresas de São Paulo.

Giddens, Anthony. 2009. The Politics of Climate Change. Cambridge: Polity Press.

ICLEI. 2013. Who we are. Disponível em: <http:// http://www.iclei.org/iclei-global/who-is-iclei.html>. Acesso em: 13 jun. 2013.

Instituto Brasileiro de Geografia e Estatística - IBGE. 2010. Censo Demográfico: Brasil. Rio de Janeiro: IBGE.

Jensen, Ole Jesper. 2004. Networks as tools for sustainable urban development. Munich, International Conference Innovation, Sustainability and Policy.

John, Peter.1998. Analysing Public Policy. Londres: Pinter (Critical Political Studies).

Kingdon, John Wells. 2011. Agendas, Alternatives and Public Policies. Boston: Longman.

Keiner, Marco e Kim, Arley. 2006. Transnational City Networks for Sustainability. European Planning Studies, 15(10): 1369-95. http://dx.doi. org/10.1080/09654310701550843

Kern, Kristine e Alber, Gotelind. Governing Climate Change in Cities: Modes of Urban Climate Governance in Multi-Level Systems. Milan, OECD International Conference: "Competitive Cities and Climate Change”

Lankao, Patricia Romero. 2007a. Are we missing the point? Particularities of urbanization, sustainability and carbon emissions in Latin American cities. Environment and Urbanization, 19(1): 159-175. http://dx.doi.org/10.1177/0956247807076915

Lankao, Patricia Romero. 2007b. How do local governments in Mexico City manage global warming? Local Environment, 12(5): 519-535. http://dx.doi. org/10.1080/13549830701656887
Lindseth, Gard. 2004. The cities for climate protection campaign (CCPC) and the framing of local climate policy. Local Environment, 9(4):325-336. http:// dx.doi.org/10.1080/1354983042000246252

Martins, Rafael Almeida. 2010. Governança climática nas cidades: reduzindo vulnerabilidades e aumentando a resiliência. Revista Geográfica Acadêmica, 4(2): 5-18.

Martins, Rafael Almeida e Ferreira, Leila Costa. 2010. Oportunidades e barreiras para políticas locais e subnacionais de enfrentamento das mudanças climáticas em áreas urbanas: evidências de diferentes contextos. Ambiente e Sociedade, 13(2): 223-242. Disponível em: <http:// http://www.scielo.br/pdf/ asoc/v13n2/v13n2a02.pdf> Acesso em: 3 jun. 2011.

Martins, Rafael Almeida e Ferreira, Leila Costa. 2011. Uma revisão crítica sobre cidades e mudança climática: vinho velho em garrafa nova ou um novo paradigma de ação para a governança local? Revista de Administração Pública, 45(3): 611-642. Disponível em:<http://www.scielo.br/pdf/rap/ v45n3/04.pdf> Aceso em: 3 jun. 2011.

Palmas (Município). 2003. Lei n. 1182 de 13 de maio de 2003. Institui a Política Municipal de Mudanças Climáticas e dá outras providências.

Parry, Martin; Canziani, Osvaldo; Palutikof, Jean Paul; van der Linden, Paul e Hanson, Clair. 2007. (Eds.). Climate Change 2007: impacts, adaptation and vulnerability. Contribution of Working Group II to the Fourth Assessment Report of the IPCC. Cambridge: Cambridge University Press.

Piva, Luís Henrique. 2007. O Programa de Eficiência Energética do Município de Palmas. In C. Klink (org.), Quanto mais quente melhor: desafiando a sociedade civil a entender as mudanças climáticas. São Paulo: Peirópolis; Braslia: Instituto Internacional de Educação do Brasil, p. 185-195.

Projeto de Sequestro de Carbono Social Urbano de Palmas - Pscup. 2002. Palmas.

Puppim de Oliveira, José Antônio. 2009. The implementation of climate change related policies at the subnational level: an analysis of three countries. Habitat International, 33(3): 253-259. http://dx.doi. org/10.1016/j.habitatint.2008.10.006

Ribeiro, Wagner Costa. 2008. Impactos das mudanças climáticas em cidades no Brasil. Parcerias Estratégicas, 27:297-321. Disponível em: <http:// www.cgee.org.br/parcerias/p27.php>

Robinson, Pamela e Gore, Cristopher. 2005. Barriers to Canadian municipal response to climate change. Canadian Journal of Urban Research, 14(1): 102-120.

Satterthwaite, David. 2008. Climate change and urbanization: effects and implications for urban governance. New York: United Nations Expert Group Meeting on Population Distribution, Urbanization, Internal Migration and Development. 
Satterthwaite, David; Huq,Saleemul; Pelling, Mark; Reid, Hannah e Lankao-Romero, Patricia 2007. Building climate resilience in urban areas among urban populations in low- and middle-income countries. London: Center for Sustainable Urban Development.

Souza, Celina. 2006. Políticas Públicas: uma revisão de literatura. Sociologias, 8(16): 20-45. Disponível em: <http://www.scielo.br/pdf/soc/n16/a03n16.pdf >. Acesso em: 10 jul. 2012.

Wilbanks, Thomas John; Romero-Lankao, Patricia; Bao, Manzhu; Berkhout, Frans; Cairncross, Sandy;
Ceron, Jean-Paul; Kapshe, Manmohan; Muir-Wood, Robert e Zapata-Marti, Ricardo. 2007. Industry, settlement and society. Parry, Martin; Canziani, Osvaldo; Palutikof, Jean Paul; van der Linden, Paul e Hanson, Clair 2007. (Eds.). Climate Change 2007: impacts, adaptation and vulnerability. Contribution of Working Group II to the Fourth Assessment Report of the Intergovernmental Panel on Climate Change. Cambridge: Cambridge University Press, p. 357-390.

Wilbanks, Thomas John e Kates, Robert White. 1999. Global change in local places: how scales matters. Climatic Change, 43(3): 601-628. 